\title{
Why School Adolescent Girls Elope? Perspective from School Teachers
}

Sudha Ghimire*

\begin{abstract}
Marriage is considered as compulsive ritual by all societies, though it has been explained differently by different cultural groups. In Nepal the prevalence of love marriage varies between communities, regions, castes and ethnic groups, but most of the time they are early before the legal age of marriage. In this context, this paper explores the views from school officials regarding the reasons of early marriage, where they have highlighted the cultural practices, social media, lack of transformative sexuality education from schools, gap in the contents of school curriculum regarding sexual and reproductive health. For the purpose of data collection teachers from Baira Mahdev School were purposively selected and in-depth interviews were conducted for exploring their views. The collected data were analyzed on thematic basis and relevant themes were generated.
\end{abstract}

Keywords: curriculum, health education, sexual and reproductive health, school, teaching learning activities, localization

\section{Introduction}

Too young to marry: Apr 10, 2016-The first Girl Summit in Nepal, co-hosted by the UK and Unicef, was held in Kathmandu on March 23. In the run-up to the event, which aims to fight child marriage worldwide, multiple district consultations were held in 15 districts with a high prevalence of child marriage. The summit brought together youths, activists, government officials, diplomats, statesmen, UN representatives, religious leaders and civil society and community members to intensify the effort to end child marriage by 2030 . Child marriage has existed from time immemorial in Nepal.

ASMITAVERMA, Kathmandu Post,Published: 10-04-2016 08:06.

When I read this article posted in Kathmandu Post, a daily national newspaper, at front page, it caught my attention. Being a scholar, I am always interested and keen on issues related to gender and sexuality. I went through this article several times and thought why, despite the huge national and international inputs in minimizing child marriage, we still

* PhD Scholar, Graduate School of Education, TU have entrenched early marriage tradition. The main purpose of writing this paper is basically to understand the reasons behind existing adolescent child marriage regardless of huge efforts by different stakeholders. As we know, marriage is considered as compulsive ritual by all societies, though different cultural groups have described it differently. The prevalence of love marriage varies between communities, regions, castes and ethnic groups but most of the time they happen early before the legal age of marriage. However, child marriage in Nepal is a customary, socially established institution that has been practiced for generations. Religion has endorsed it and society has ensured its stability (Maharjan, Kharki, Shakya, \& Aryal, 2012). Although government of Nepal along with its supporting organizations are working against early marriage, the existing data show that still $46 \%$ of women get first sexual relation and get married before they turn 18 (NDHS, 2016), against the legal age of marriage. Similarly, among women were age $25-49,13 \%$ were married by the age of 15 (NDHS, 2016). Nowadays the trend of early marriage is constant but the approach is somehow changed. Earlier there used to be more arranged marriage, but recently 
love marriage, and eloping with boyfriend are equally found in community (Maharjan, Kharki, Shakya, \& Aryal, 2012). Similarly, more than $25 \%$ of marriages are based on the girl's decision (Perczynska, 2014). Such trend is deeply rooted in some indigenous groups like Tamang (Kafle, 2008). Though early and universal marriage is a traditional norm of our society (Stone, Ingham, \& Simkhada, 2003) and delayed marriage is increasing, still early marriage and teen-age pregnancy is high, if compared globally (Pathak \& Pokharel, 2012).

These situations triggered me to find the deeprooted cause of adolescent marriage in our context. Professionally being a nurse and health educator, I interact with many people, social activists and stakeholders dealing with these issues. This time I selected school teachers as my primary respondents who are in daily contact with adolescents so that I could get the reasons from their perspective about why our adolescent girls get married or elope with boyfriend, despite the fact that school has been providing continuous education on sexual and reproductive health. I presented these questions and queries in-front of school teachers:

\section{Research Question}

1. Why does an adolescent girl elope?

2. Does sexuality education really work in preventing elopement among school adolescent girls? If not why?

3. What is the teachers' opinion about the effectiveness of school curriculum in preventing early marriage?

\section{Methods}

Being a woman, I think I have equal responsibility towards my society, as male do. It can be a voice of culturally silent people' revealing the things that bothers the life of women. Keeping that in mind, I had an in-depth interview of school teachers for exploring the reasons of early marriage that is proved to be one of the reasons for problems related to reproductive health. I have selected Baira Mahadev Basic School purposively for study area, as the school is situated in semiurban area i.e $28 \mathrm{~km}$ away from the Hassle and Basal of Kathmandu valley with more 'Tamang' indigenous population. Being a qualitative researcher, I realized that qualitative research looks for a naturalistic approach that seeks to understand phenomena in context specific setting such as real world (Creswell, 2017). I equally focused the cultural background of respondents and was there for full time for interview.

For collecting data as suggested by Brikci and Green (2007), interview method is a major component in a range of different methodological strategies in gathering hidden treasure. However, it is not possible to anticipate every possible question. Therefore, I keep on probing in each question to immerse myself in the depth of information provided. With the guideline from different literature I went through, I developed semi-structured questions and used problematic links with contents. The set questions were unambiguous and have link between existing problems directly or indirectly. I started with general questions that helped me for ice breaking followed by focused and precise questions. I followed funnel shaped approach in interviewing respondents. Throughout interview process, I was fully conscious of bracketing myself.

An audiotape recording allows an interviewer to focus on the conversation with an informant and carries a more complete record of the informant's actual words (Brenner, 2006). I recorded full interview of participants with informed consent with them to maintain ethics throughout study.

The analysis of qualitative data is often seen as the most difficult part of the exercise. Yet it is very enjoyable to see the patterns that 
emerge and to draw out some meaningful conclusion from the discussion (Brikci \& Green, 2007). There are many different ways to analyze qualitative data. We can use thematic, descriptive approach or more indepth methods, or there are lots of software developed for analyzing data (Pope, sue, \& Nicholas, 2000). Among them I thought to carry out thematic analysis which is done primarily by detailed reading of raw data to derive concepts (Thomas, 2006). I read and re-read the transcribed interview several times; highlighting key issues pointed out by both respondents and again looked for common and different views they provided. It enabled me to formulate core message of the interview and made themes by open coding, axial coding and selective coding.

\section{Results and Discussion}

The wider gap in transformative learning was found while interviewing school officials. Despite the sexual and reproductive health education at school, there is early marriage making adolescents at high risk of diseases and poor health. That not only leads to drop out from school and poor educational achievement but also their uncertain future. The information gathered from respondents are categorized under the following themes.

\section{Foot-steps without judgment}

In Nepal, the term 'love marriage' is commonly used to refer to a marriage not arranged by the bride and groom's families (Pandey, 2017). While interviewing school teachers about existing scenario of adolescent marriage in their community, they have said:

Here, girls elope just at the age of 14-15. We can't find girls above 18 years who are not married in this community. Most of the time they fall in love during school days and elope, after a few months they drop school. (Health Teacher).
He further added that when adolescents see their senior classmates or friends eloped with boyfriend, they just imitate them and run away with boyfriend, most of the time parents are also unaware of that. When I asked what could be another reason for elopement of girls, the principal added:

"Nowadays most of the youngsters carry mobile phone and internet. They communicate and chat in facebook, and it will not take any time to fall in love and infatuation, leading to early marriage".

Culturally, Tamang indigenous groups specially follow love marriages (Kafle, 2008). As the data show, girls and boys fall in love and get married at the school going age which not only affects their education but also health (Maharjan, Kharki, Shakya, \& Aryal, 2012). One of the teachers from school shared this.

Furthermore, social and cultural norms impose barrier to the transfer of sexual health information to adolescents and it is the education that breaks the invisible barriers (Stone, Ingham, \& Simkhada, 2003). Studies have also shown that it is necessary to focus on young people before they become sexually active, before myths become deep-rooted and unsafe patterns of sexual behavior are established. That's why sexual and reproductive health education is incorporated from early days of puberty and pre-puberty stage, but the question is: Does the education we have been providing to adolescents really address their physical, physiological and social issue?

Though we have been teaching sexual and reproductive health and drawbacks of early marriage, eloping with the boyfriend is a trend of this society. They are just following the activities happening in their community without analyzing what could be the circumstances .Principal

Multicultural interaction with different social 
groups is proved as effective in promoting educational achievement among students. It is also concerned with the contribution of students towards effective social action (Kislev, 2016). Here, majority of students are from Tamang indigenous group with less interaction with other social groups. This hinders them to learn from other cultures as stated by health teacher.

Despite improvements in lives of young people, they are in first line for vulnerability which is increasing day by day (Pathak \& Pokharel, 2012). Until and unless we address adolescents and guide them via friendly social systems, public policies, service delivery systems, and enriched need based education, the risk of unhealthy attitude remains unchanged.

\section{Tension in transforming knowledge related to sexuality}

When I asked the teachers what they actually taught in health, whether they felt comfort while teaching comprehensive sexuality education, the teacher responded:

In most of the government schools, teachers are all reluctant to discuss the contents of the chapter on sexuality and reproductive health in any detail. Sometimes teacher even leaves the chapter without teaching, because there are many schools where teachers from different educational background teach health subject. School administration is unable to manage the subject teacher with their specialization. Principal

Furthermore, in school sexuality education is taught by male teacher, which makes girl students more difficult to raise questions.

When I teach the content of sexual education, there is pin drop silence in classroom. No one raises any questions. The interaction between teacher and students is almost zero. Health Teacher

Thus, when there is less class interaction there will definitely be less learning (Schutte et al., 2014.).

On the same issue another respondent asserted that

Still there is a gap in knowledge we have provided and perception of children, that could be the reason that behavioral changes are not long term because we haven't addressed social, cultural and educational background of that community while delivering health education and reproductive education "' (Health Teacher)

Sexuality education has been provided at school level but a little known message is covered. Most of the teachers did not want to deal with sensitive topics and feared from their colleagues and society if they have to teach sexual andreproductive health. Some lacked the skills to give instruction regarding sexual and reproductive health. Many students also felt uncomfortable with the topics. The challenge is to strengthen sexuality education, make it more appropriate for the students and ensure that teachers are more comfortable and able to give instruction on the topic (Pokharel, Kulczycki, \& Shakya, 2006 ).

\section{Hidden part of sexuality education}

Inclusion of local curriculum is one of the key steps taken by CDC for addressing the need of community and feeling of ownership in education. Furthermore, CDC has brought innovative aspects in health education giving 20 $\%$ space for health contents to link community with that of school. It is difficult unless it adopts participatory approach in education. Regarding the contents of curriculum for health perspective, it is found that:

Health curriculum has addressed most of the things relating to health and reproductive issues but if we conduct micro-level analysis it's lacking most of the things either in content or knowledge delivery. We don't know whether the contents that are included regarding sexual 
health in curriculum are not enough or there is gap in teaching learning process. The education we are delivering is not matching with our community. Principal

It is found that most of the time teachers are using lecture method in health education, which is proved less effective in creating interest for students in learning health education (Asare, Stillman, Keogh, Doku, \& Kyereme, 2017).

Most of the contents of sexual and reproductive health are concerned on just physical growth and development of students. It would be more effective if social, cultural and psychological aspects of sexuality were also included. Health Teacher

Furthermore, teachers are not well trained and qualified in teaching sexual and reproductive health in schools. Besides, health subject is given less priority by teachers and students in comparison to mathematics and science as stated by Principal from Baira Mahadev school. There are still many schools where teachers from different educational background are teaching health education.

We are forced to teach different subject out of our interest due to scarcity of teachers (Health teacher)

Similarly, in this community there is entrenched gender based discrimination between boys and girls, where boys are sent to boarding school and girls to government school. Such discriminations are found not only in education sector, but also in basic health services. So, it's crucial to add those issues in curriculum that is designed for this particular community.

I found positive attitude of teachers towards sexuality education, but they are more worried that schools have been providing them pressure to sexuality related education without providing any basic level training.

\section{Conclusion}

Early marriage and teenage pregnancy among adolescent students indicate that there is the gap in knowledge that we have been providing. Sexuality education without trained teacher creates tension for both knowledge providers and receivers because until and unless there is change in attitude, practice and behavior of students, the education objectives remain underachieved. So, it's time for concerned policy makers, service providers, academicians and development practitioners to address those issues. Personally, my reflection from this study is that though we have done many things for reducing child marriage, it is rooted in local culture and furnished by social media in such a way that it is difficult to eradicate, but we can reduce it in some way.

\section{REFERENCES}

Asare, A., Stillman, M., Keogh, S., Doku, D., \& Kyereme, A. (2017). From Paper to Practice: Sexuality Education Policies and their Implementation in Ghana. New York: Guttmacher Institute. Retrieved from https:// www.guttmacher.org/sites/default/files/report_ pdf/sexuality-education-ghana-report.pdf

Brenner, E. (2006). Handbook of complementory methods in education research. Santa Barbara: AERA.

Brikci, N., \& Green, J. (2007). A Guide to Using Qualitative Research Methodology. Medecins Sans Frontierres, 1-37.

Creswell, J. (2017). Educational research: Planning, Conducting, and evaluating quantitative and qualitative research. Pearson Education (4th ed.). India: Pearson Education.

Kafle, M. (2008). Child marriage practice among tamang of Ichangu Narayan VDC, Nepal. Social Inclusion Research . 
Kislev, E. (2016). The effect of education policies on higher-education attainment of immigrants in western Europe: A cross-classified multilevel analysis. Journal of European Social Policy, 26(2), 183-199. doi:DOI: $10.1177 / 0958928716637142$

Maharjan, R., Karki, K., Shakya, T., \& Aryal, B. (2012). Child marriage in Nepal. Kathmandu: Plan Nepal.

Pandey, S. (2017). Persistent nature of child marriage among women even when it is illegal: The case of Nepal. Children and Youth Services Review, 73, 242-247. https://doi.org/10.1016/j. childyouth.2016.12.021

Pathak, R., \& Pokharel, T. (2012). Sexual and reproductive health status of adolecents and youth in Nepal. Nepal Population Journal, 17(16). Retrieved from http://dms.nasc.org. $\mathrm{np} /$ sites/default/files/documents/Trilochan $\% 20$ Article\%20SRH.pdf

Perczynska, O. (2014). Child marriage in Nepal: What do you do when it's by choice? Kathmnadu. Retrieved from https://www. theguardian.com/global-developmentprofessionals-network/2014/feb/24/childmarriage-trends-nepal
Pokharel, S., Kulczycki, A., \& Shakya, S. (2006 ). School-based sex education in Western Nepal: uncomfortable for both teachers and students. PubMed, 14(28), 156-61. doi:10.1016/S09688080(06)28255-7

Pope, C., sue, Z., \& Nicholas, M. (2000, Jan 8). Analysis of Qualitative Data. British Medical Journal (BMJ), 320(7227), 114-6. doi:10.1136/ bmj.320.7244.1240

NDHS. (2016). Nepal demographic health survey. Kathmandu.

Schutte, L., Meertens, R. M., Mevissen, F. E. F., Schaalma, H., Meijer, S., \& Kok, G. (2014). Long Live Love. The implementation of a school-based sex-education program in the Netherlands. Health Education Research, 29(4), 583-597. https://doi.org/10.1093/her/ cyu021.

Stone, N., Ingham, R., \& Simkhada, P. (2003). Knowledge of sexual health issues among unmarried young people in Nepal. Asia-Pacific Population Journal, 18(2), 33-39. doi:92-1-120

Thomas, R. (2006). A General Inductive Approch for Analyzing Qualitaive Evaluation Data. American Journal of Evaluation, 27(2), 237246. doi:10.1177/1098214005283748. 